\title{
Association of duration of television viewing in early childhood with the subsequent development of asthma
}

\author{
A Sherriff, ${ }^{1}$ A Maitra, ${ }^{2}$ A R Ness, ${ }^{3}$ C Mattocks, ${ }^{4}$ C Riddoch, ${ }^{4} \mathrm{~J}$ J Reilly, ${ }^{5} \mathrm{~J}$ Y Paton, ${ }^{5}$ \\ A J Henderson ${ }^{6}$
}

${ }^{1}$ Dental School, Faculty of Medicine, University of Glasgow, Glasgow, UK; ${ }^{2}$ Department of Paediatric Respiratory Medicine, Sheffield Children's Hospital, Sheffield, UK; ${ }^{3}$ Department of Oral and Dental Science, University of Bristol, Bristol, UK ${ }^{4}$ School for Health, University of Bath, Bath, UK; ${ }^{5}$ Division of Developmental Medicine. University of Glasgow, Glasgow, UK: ${ }^{6}$ Department of

Community-Based Medicine, University of Bristol, Bristol, UK

Correspondence to:

Dr A Sherriff, Dental School

Faculty of Medicine, University of Glasgow, Glasgow G2 3JZ,

UK; a.sherriff@dental.gla.ac.uk

Received 7 July 2008

Accepted 9 December 2008

\section{ABSTRACT}

Objective: To investigate whether duration of television (TV) viewing in young children is associated with subsequent development of asthma.

Methods: Children taking part in the Avon Longitudinal Study of Parents and Children (ALSPAC) with no wheeze up to the age of 3.5 years and follow-up data at 11.5 years of age took part in a prospective longitudinal cohort study. The main outcome measure was asthma, defined as doctor-diagnosed asthma by 7.5 years of age with symptoms and/or treatment in the previous 12 months at 11.5 years of age. Parental report of hours of TV viewing per day by the children was ascertained at 39 months.

Results: In children with no symptoms of wheeze at 3.5 years of age and follow-up data at 11.5 years of age, the prevalence of asthma was $6 \%$ (185/3065). Increased TV viewing at 3.5 years was associated with increased prevalence of asthma at 11.5 years of age ( $p$ for linear trend $=0.0003$ ). Children who watched television for $>2 \mathrm{~h} /$ day were almost twice as likely to develop asthma by 11.5 years of age as those watching TV for $1-2 \mathrm{~h} /$ day (adjusted odds ratio $1.8(95 \% \mathrm{Cl} 1.2$ to 2.6$)$ ).

Conclusion: Longer duration of TV viewing in children with no symptoms of wheeze at 3.5 years of age was associated with the development of asthma in later childhood.

Asthma is a common cause of respiratory morbidity in children, but the environmental exposures associated with observed increases in the prevalence of asthma over time $e^{1}$ have not been fully identified. Several epidemiological studies have suggested a link between overweight and asthma in both adults and children, ${ }^{2-5}$ with some reporting a stronger association in girls than boys. ${ }^{5}$ However, despite a large body of literature on the subject, there remains considerable debate about the existence of a true association between overweight and asthma in children (reviewed recently by Chinn $^{6}$ ) and its potential mechanisms. ${ }^{7}$ This includes the possibility that any association between overweight/obesity and asthma might reflect lifestyles associated with obesity (in particular, lower levels of physical activity) rather than obesity per se. Underlying the recent increases in the prevalence of overweight and obesity in children in many countries is a perception of a secular trend towards lower levels of physical activity. However, as pointed out in a recent review by Dollman and colleagues, ${ }^{8}$ methodological differences between studies and lack of historical data make it difficult to construct a single measure that adequately reflects global changes in activity and energy expenditure. Measures such as walking and cycling and participation in school-based physical education may be declining. For other measures the evidence is less clear, although the proportion of time spent in vigorous activities by UK children has been reported to have declined over recent years, ${ }^{9}$ and contemporary preschool children in the UK have low levels of objectively measured physical activity and high levels of objectively measured sedentary behaviour. ${ }^{10}$

Most studies of activity and asthma have concentrated on physical activity or exercise, but there has been a recent suggestion that breathing patterns associated with sedentary behaviour could lead to developmental changes in the lungs and wheezing illnesses in children. ${ }^{11}$ It should be appreciated in this context that, although sedentary behaviour and physical activity have been shown to have a weak inverse association in longitudinal studies, ${ }^{12}$ they are not converse measures of the same phenomenon but represent discrete aspects of activity behaviour with independent determinants. ${ }^{13}$ The relationship between physical activity, sedentary behaviour and asthma is complicated. Reduced physical activity and increased sedentary time could be associated with lower levels of physical fitness or increased body size, both of which could result in increased exertional breathlessness that could be mistaken for a symptom of asthma. In addition, the wellrecognised phenomenon of exercise-induced bronchoconstriction in subjects with established asthma could limit participation in physical activities through both physical and psychological barriers. ${ }^{14}{ }^{15}$ Some cross-sectional studies have reported associations of both low levels of physical activity $^{16-18}$ and high levels of sedentary behaviour ${ }^{19}$ with asthma. Others have reported associations between increased physical activity and asthma ${ }^{20}$ or asthma symptoms. ${ }^{21}$ Cross-sectional studies have distinct limitations in the investigation of the role of physical activity levels in the inception of asthma as opposed to exacerbation of existing asthma symptoms, in addition to the potential for discovery of associations due to reverse causation. Lucas and Platts-Mills ${ }^{22}$ have described a number of plausible mechanisms by which physical inactivity could be directly involved in the aetiology of asthma and, although this has been addressed by only a few studies of adolescents and young adults, there is evidence that low levels of physical activity or fitness in childhood increase the risk of 
new-onset asthma. ${ }^{23}{ }^{24}$ We are not aware of any studies that have addressed this question in early childhood, which is recognised as an important developmental window for asthma and a time when levels of physical activity are low and levels of sedentary behaviour high. ${ }^{10}$ We therefore investigated the association between duration of TV viewing (as a proxy measure of sedentary behaviour) in early childhood and the development of asthma at 11.5 years in a sample of children from a longitudinal birth cohort with no symptoms of wheeze to the age of 3.5 years. Our specific hypothesis was that longer duration of TV viewing in young children would be associated with an increased prevalence of asthma later in childhood. A secondary aim of the study was to explore potential gender differences in the associations between duration of TV viewing and asthma.

\section{METHODS}

\section{Study sample}

The Avon Longitudinal Study of Parents and Children (ALSPAC) is a prospective study of 14541 pregnancies with 13988 live births surviving to at least 1 year. Full study details have been published previously. ${ }^{25}$

\section{Asthma outcomes}

Questionnaires on wheezing symptoms (wheezing with whistling on the chest) of the study children were completed by a parent for 0-6 months and at approximately annual intervals thereafter. At the age of 11.5 years, asthma was defined as a doctor diagnosis of asthma by 7.5 years of age with continued symptoms or medication use in the previous 12 months. At the 8.5-year visit to the research clinic, 7488 children attended and 7307 had lung function measured. Of these, 4719 children unselected for asthma status or wheezing began a bronchial challenge test with methacholine using the method of Yan and others; ${ }^{26}$ bronchial hyper-responsiveness (BHR) to methacholine, defined as a dose provoking a fall in forced expiratory volume in $1 \mathrm{~s}\left(\mathrm{FEV}_{1}\right)\left(\mathrm{PD}_{20}\right)$ of $<1.2 \mathrm{mg}$ methacholine, was measured in 4364 children.

To address the issue of reverse causation, our study sample comprised those children with no wheezing symptoms reported up to 3.5 years (asymptomatic) at the point when duration of TV viewing was measured.

\section{Sedentary behaviour}

When these children were 39 months old, the most common sedentary behaviour was likely to have been viewing TV as personal computers and games consoles were not in widespread use by this age group at this time (mid 1990s). Also, at this time, the technology to provide objective measures of activity/ sedentary behaviour had yet to be widely applied within large epidemiological studies and on such young children. For these reasons, we have chosen to use duration of TV viewing during the week as a proxy measure of sedentary behaviour for this age group at this time. In a questionnaire sent to mothers when the child was 39 months old, they were asked to report how many hours of television their child watched in a weekday and weekend day (none, <1 h/day, 1-2 h/day, >2 h/day). Responses for weekdays and weekend days were highly correlated; weekday television viewing was therefore used as a proxy measure of sedentary behaviour in early childhood.

Sedentary behaviour at 11.5 years was assessed objectively using accelerometry (MTI Actigraph AM7164 2.2, Fort Walton Beach, Florida, USA) and was defined as the average daily number of minutes at $\leqslant 199$ counts $/ \mathrm{min}^{27}$

\section{Statistical analyses}

The analysis of associations between duration of TV viewing in early childhood and the development of asthma in later childhood was restricted to children who were asymptomatic for wheeze at every questionnaire to 3.5 years to minimise the risk of reverse causation. Based on prior evidence that there may be a differential effect of sedentary behaviour and asthma outcomes with gender, boys and girls were analysed separately and then together, formally testing for interactions. Binary logistic regression models were used to assess the effect of duration of TV viewing on rates of asthma in previously asymptomatic children (up to 3.5 years of age). The modal category of TV viewing at 3.5 years ( $1-2 \mathrm{~h}$ /day) was used as the reference category in the logistic regression models. $p$ Values for trend were calculated.

Univariable models were run initially to obtain crude odds ratios and $95 \%$ confidence intervals ( $95 \% \mathrm{CI}$ ), after which adjustments were made to the effect sizes for body mass index (BMI) measured at 11.5 years (continuous and categorical, respectively), followed by the addition of possible confounder variables to the model in turn to determine the level of attenuation of the effects. In addition to current BMI, maternal smoking during pregnancy and maternal history of asthma and allergies were also considered in the model. Several social and lifestyle variables were added to the final model to adjust for a potential mediating effect of social variables on parental selfreported TV viewing. These were: maternal housing inadequacy, financial difficulties, low educational attainment, psychopathology of mother (depression) and lack of social network practical support during pregnancy. The univariable models were then rerun using only those children who contributed data to the fully adjusted model in order to check that attenuation of effects was due to confounding rather than differential loss to follow-up.

To explore whether TV viewing at 3.5 years of age was a proxy for habitual sedentary behaviour throughout the life

Table 1 Characteristics of study sample

\begin{tabular}{lc}
\hline & $\begin{array}{c}\text { Children asymptomatic at } \\
\mathbf{3 . 5} \text { years with follow-up } \\
\text { asthma data at 11.5 years }\end{array}$ \\
\hline Asthma at 11.5 years, \% (n) & $6.0(185 / 3065)$ \\
BHR at 8.5 years, \% (n) & $13.5(307 / 2270)$ \\
TV viewing at 3.5 years (N=10 070), \% (n) & \\
None & $2.7(80)$ \\
$<1 \mathrm{~h} /$ weekday & $28.3(850)$ \\
$1-2 \mathrm{~h} /$ weekday & $46.4(1394)$ \\
$>2 \mathrm{~h} /$ weekday & $22.6(678)$ \\
Median (IOR) BMl at 11.5 years & $18.1(16.5-20.5)$ \\
Maternal smoking during pregnancy & \\
(n=11 229), \% (n) & \\
None & $85.9(2592)$ \\
$<10 /$ day & $5.9(179)$ \\
$10-19 /$ day & $6.0(182)$ \\
$\geqslant 20 /$ day & $2.2(65)$ \\
Maternal asthma and allergies, \% (n) & $42.8(1279 / 2987)$ \\
Housing inadequacy in pregnancy, \% (n) & $2.8(86 / 3035)$ \\
Low educational attainment, \% (n) & $8.7(265 / 3048)$ \\
Psychopathology of mother during pregnancy, \% (n) & $17.3(521 / 3005)$ \\
Financial difficulties during pregnancy, \% (n) & $6.3(187 / 2972)$ \\
Lack of social network practical support during & $4.6(139 / 3018)$ \\
pregnancy, \% (n) & \\
\hline B &
\end{tabular}

BHR, bronchial hyper-responsiveness; BMI, body mass index. 
Table 2 Odds ratios and 95\% confidence intervals (unadjusted and adjusted) for asthma at 11.5 years of age according to daily TV viewing at 3.5 years of age in children with no symptoms of wheeze up to 3.5 years

\begin{tabular}{|c|c|c|c|}
\hline \multirow[b]{4}{*}{ TV viewing at 3.5 years of age } & \multicolumn{3}{|c|}{ Asthma at $\mathbf{1 1 . 5}$ years of age } \\
\hline & All & Boys & Girls \\
\hline & $6.0(185 / 3065)$ & $6.1(88 / 1436)$ & $6.0(97 / 1629)$ \\
\hline & $\mathrm{n}=3002$ & $n=1401$ & $n=1601$ \\
\hline Not at all, \% (n) & $5.0(4 / 80)$ & $4.8(2 / 42)$ & $5.3(2 / 38)$ \\
\hline Crude OR $(95 \% \mathrm{Cl})$ & $0.9(0.3$ to 2.5$)$ & $0.9(0.2$ to 3.7$)$ & $0.9(0.2$ to 4.0$)$ \\
\hline Restricted OR $(95 \% \mathrm{CI})^{*}$ & 0.6 (0.1 to 2.3 ) & 0.5 (0.07 to 3.8$)$ & 0.6 (0.08 to 4.5$)$ \\
\hline Adjusted OR (95\% Cl) BMl $\dagger$ & $0.8(0.2$ to 2.6$)$ & $0.5(0.1$ to 3.8$)$ & $1.1(0.3$ to 4.9$)$ \\
\hline Adjusted OR $(95 \% \mathrm{Cl}) \$$ & $0.5(0.1$ to 2.2$)$ & $0.5(0.06$ to 3.4$)$ & 0.6 (0.08 to 4.9$)$ \\
\hline$<1$ h/day, \% (n) & $4.2(36 / 850)$ & $4.4(16 / 364)$ & $4.1(20 / 486)$ \\
\hline Crude OR $(95 \% \mathrm{Cl})$ & $0.8(0.5$ to 1.1$)$ & $0.8(0.4$ to 1.4$)$ & 0.7 (0.4 to 1.2$)$ \\
\hline Restricted OR (95\% Cl) & $0.7(0.5$ to 1.1$)$ & $0.7(0.4$ to 1.4$)$ & $0.7(0.4$ to 1.3$)$ \\
\hline Adjusted OR (95\% Cl) BMI & $0.7(0.5$ to 1.2$)$ & $0.7(0.4$ to 1.4$)$ & $0.8(0.4$ to 1.4$)$ \\
\hline Adjusted OR (95\% Cl) & $0.7(0.44$ to 1.1$)$ & $0.7(0.4$ to 1.4$)$ & $0.7(0.3$ to 1.3$)$ \\
\hline 1-2 h/day, \% (n) & $5.6(78 / 1394)$ & $5.6(37 / 666)$ & $5.6(41 / 728)$ \\
\hline Reference category & 1.00 & 1.00 & 1.00 \\
\hline$>2$ h/day, \% (n) & $9.0(61 / 678)$ & $8.8(29 / 329)$ & $9.2(32 / 349)$ \\
\hline Crude OR (95\% Cl) & 1.7 (1.2 to 2.4$)$ & $1.6(1.0$ to 2.7$)$ & $1.7(1.1$ to 2.7$)$ \\
\hline Restricted OR (95\% Cl) & 1.8 (1.2 to 2.6$)$ & $1.6(0.9$ to 2.8$)$ & $2.0(1.2$ to 3.4$)$ \\
\hline Adjusted OR (95\% Cl) BMI & $1.8(1.3$ to 2.7$)$ & $1.8(1.1$ to 3.1$)$ & $1.9(1.1$ to 3.1$)$ \\
\hline Adjusted OR (95\% Cl) & 1.8 (1.2 to 2.6$)$ & $1.7(1.0$ to 3.0$)$ & $1.9(1.1$ to 3.3$)$ \\
\hline$p$ for linear trend & 0.0003 & 0.02 & 0.005 \\
\hline
\end{tabular}

*Univariable analysis restricted to sample in multivariable (fully adjusted model) ( $\mathrm{n}=2305$ ).

$\uparrow$ Adjusted for body mass index (quartiles) at 11.5 years only $(n=2471)$.

:Adjusted for body mass index (quartiles) at 11.5 years, maternal asthma/allergies, maternal smoking during pregnancy and maternal housing inadequacy, financial difficulties, low educational attainment, psychopathology of mother and lack of social network practical support during pregnancy $(n=2305)$.

course or whether it was an independent predictor of asthma at 11.5 years of age, we included an objective measure of sedentary behaviour derived from accelerometry in the final model.

Finally, the potential modifying effect of BHR on the association between duration of TV viewing and asthma was considered using an interaction term. All analyses were undertaken using Stata V.9.0 (StataCorp).

\section{RESULTS}

The characteristics of the study sample are shown in table 1. A total of 5207 from 8510 children (61\%) with available data at every time point between 6 and 42 months had no reported wheezing and comprised the asymptomatic sample for longitudinal analysis. Of these 5207 children, 3065 (59\%) had follow-up asthma data at 11.5 years. The prevalence of asthma (as defined in methods) in these children was 6\% (185/3065), with no appreciable difference between boys and girls.

\section{Duration of TV viewing at $\mathbf{3 . 5}$ years and asthma in later childhood}

As the duration of TV viewing per day increased, the prevalence of asthma at 11.5 years of age increased ( $p$ for linear

Table 3 Percentage of children developing asthma by 11.5 years of age (who were asymptomatic at 3.5 years of age) with and without bronchial hyper-responsiveness (BHR) according to TV viewing

\begin{tabular}{lll}
\hline \multirow{2}{*}{ TV viewing } & \multicolumn{2}{l}{ Percentage of children with asthma, \% (n) } \\
\cline { 2 - 3 } & No BHR & BHR \\
\hline Not at all & $3.2(1 / 31)$ & $33.3(2 / 6)$ \\
$<1 \mathrm{~h} /$ day & $2.0(8 / 410)$ & $11.5(6 / 52)$ \\
$1-2 \mathrm{~h}$ /day & $2.7(18 / 656)$ & $17.0(16 / 94)$ \\
$>2 \mathrm{~h}$ /day & $4.6(14 / 304)$ & $28.3(13 / 46)$ \\
\hline
\end{tabular}

trend $=0.0003$ ). Children who had no symptoms of wheeze from birth and who were reported to watch $>2 \mathrm{~h} /$ day TV at the age of 3.5 years were more likely to have developed asthma by 11.5 years of age than children watching fewer hours of TV per day (adjusted odds ratio (OR) at 11.5 years 1.8 (95\% CI 1.2 to 2.6)) with little evidence of attenuation after adjustment for current BMI and possible confounders (table 2). Furthermore, there was no evidence for modification by gender ( $p$ for interaction $=0.9$ ) or contemporaneous BMI ( $\mathrm{p}$ for interaction $=0.6$ ).

TV viewing at the age of 3.5 years was not related to objectively measured sedentary behaviour at 11.5 years in children without symptoms at 3.5 years. Those who reported no TV viewing spent a mean (SD) of 429.1 (72.2) $\mathrm{min} /$ day sedentary compared with 426.9 (65.5) $\mathrm{min} /$ day for those watching $<1 \mathrm{~h} /$ day, 431.8 (64.5) $\mathrm{min} /$ day for those watching 1-2 h/day and $426.2(72.2) \mathrm{min} /$ day for those watching $>2 \mathrm{~h} /$ day. Children with asthma at 11.5 years of age spent a mean of 5 minutes more per day sedentary than those without asthma (this is equivalent to one-twelfth of a standard deviation in sedentary behaviour). The effect of TV viewing in early childhood on the development of asthma was not attenuated by objectively measured sedentary behaviour at 11.5 years of age.

Children in whom BHR was measured had an asthma prevalence at 11.5 years of $10.5 \%$ whereas those who did not have BHR measured had an asthma prevalence of $15.5 \%$ $(p<0.001)$. There were 1599 children asymptomatic to 3.5 years who had data on TV viewing, BHR measured and asthma follow-up data at 11.5 years. In this group, 16.2\% (6/37) of children with BHR were reported to watch no TV at all compared with $11.3 \%$ (52/462), 12.5\% (94/750) and 13.1\% (46/ 350 ) of children watching $<1 \mathrm{~h} /$ day, $1-2 \mathrm{~h} /$ day and $>2 \mathrm{~h} /$ day, respectively. Owing to small numbers for the first category, the confidence intervals were wide $(7.7 \%$ to $31.3 \%)$, presenting 
some doubt about the precision of the point estimate. However, although the numbers were small, the presence of BHR did not appear to modify the association of TV viewing at 3.5 years of age with asthma at the age of 11.5 years ( $p$ for interaction $=0.9$, table 3).

\section{DISCUSSION \\ Principal findings}

This study has shown for the first time a positive association between increased duration of reported TV viewing in early childhood and the development of asthma by 11.5 years of age in children with no symptoms of asthma in early childhood. In considering the effect of the exposure on the development of asthma only in the sample of children who had no symptoms at 3.5 years, the possibility that any observed association was due to wheezy children electing to be more sedentary as a result of their condition was minimised.

\section{Methodological considerations}

These data were from a large longitudinal birth cohort study based in the UK. Data were collected prospectively to minimise the effects of recall bias and the linking of exposures to outcomes. Because of the longitudinal design, it was possible to select children who had no symptoms of wheezing at the time of exposure assessment. This allowed the investigation of whether sedentary behaviour influenced the development of asthma, without contamination of the exposure measure by wheezy children (who may have self-limited their physical activity levels or had limitations imposed by their parents). In the Head Start study which included children as young as 3 years, reported wheezing was associated with reduced levels of physical activity measured by actigraphy. ${ }^{18}$ We chose to adjust for BMI in logistic regression models owing to the previously reported link between obesity and asthma ${ }^{6}$ and the finding that a strong inverse association between physical activity and obesity has been reported in this cohort. ${ }^{28} \mathrm{We}$ therefore reasoned that obesity could be on the causal path between reduced physical activity and asthma. Alternatively, obese children were more likely to have been obese in earlier childhood, ${ }^{29}$ and increased body mass even in young children may be associated with sedentary behaviour patterns. ${ }^{30}$

There is some evidence for social patterning of self-reported physical activity measures and measures of sedentary behaviour despite very small or negative associations between socioeconomic status and objectively measured physical activity levels. ${ }^{27}$ In the present study, self-reported TV viewing was socially patterned. We therefore adjusted the associations for a number of different maternal socioeconomic variables known to be also associated with asthma; however, these adjustments did not attenuate the observed effect. Finally, we found that there was no attenuation of effect when we considered objectively measured sedentary behaviour at 11 years in the model as a possible confounder, suggesting that early sedentary behaviour may have an independent association with the development of asthma rather than reflecting a habitual long-term accumulation of sedentary behaviour.

When these children were 3 years old (in 1994) there was no robust practical method of objectively measuring physical activity (or sedentary behaviour) on large numbers of young children within an epidemiological setting. Parental reporting of the duration of TV viewing of their child was therefore used as a proxy measure of sedentary behaviour. Despite the limitations of this proxy measure, we considered that TV viewing was possibly the main sedentary behaviour that these young children would be involved in at this time, given that widespread use of PCs and games consoles did not evolve until later. TV viewing behaviour in young children is known to be relatively stable, tracks over time and is associated with a number of other variables in the direction expected. For example, TV viewing in young children has been reported to relate to contemporaneous objective measures of physical activity in young children, ${ }^{31}$ and in this cohort it was weakly associated with physical activity levels in later childhood ${ }^{11}$ and was predictive of obesity at 7 years of age. ${ }^{29}$ Due to the nature of this variable, we would expect reporting bias by parents of their child's TV viewing habits to have led to an underestimate of the true effect on the development of asthma.

It should be stressed that physical activity and sedentary behaviour are not measures of the same phenomenon. We would expect that increased sedentary behaviour would be linked to decreased activity levels, but these associations are likely to vary over the life course.

\section{Interpretation of findings in relation to other studies}

A number of cross-sectional studies have reported positive associations between low physical activity and asthma and related phenotypes, ${ }^{16-19}$ including BHR. ${ }^{32}$ Other studies have reported the converse-that increased physical activity is associated with asthma ${ }^{20}$ - particularly when associated with outdoor exposure to pollutants such as ozone. ${ }^{33}$ One of the most recent cohort studies concluded that wheezing children were no less physically active than non-wheezing children, but only $39 \%$ of the original cohort participated in this study ( $n=305 / 929)$ and, once the data were split by gender, the power of the study was very low which may have resulted in clinically important results being missed. Physical training has been considered as a therapeutic intervention for asthma and has been shown to improve physical fitness, although beneficial effects on asthma control and pulmonary function of vigorous training were less compelling. ${ }^{34}$ One of the difficulties in interpreting the data on the relationships between physical activity and asthma to date is that most studies are cross-sectional in design and there have been substantial differences in study design, including measures used to assess physical activity or sedentary behaviour. However, two longitudinal studies have reported associations of new-onset asthma with elements of physical activity and fitness. Vogelberg and colleagues reported reduced incidence of wheezing in adolescents who exercised more than weekly. In contrast, there was a positive univariable association between new-onset wheeze and visiting discotheques, and all the associations between physical activity and wheeze were attenuated completely by adjustment for smoking. ${ }^{23}$ A Danish study found that low physical fitness at around 10 years of age in asymptomatic children was related to the development of asthma over the subsequent decade, ${ }^{24}$ although this was based on an isolated measure of physical fitness rather than habitual physical activity. Physical fitness and activity are more likely to be correlated than sedentary behaviour. ${ }^{35}$ Also, the lower incidence of asthma during adolescence compared with early childhood raises the possibility of missing a critical window of exposure in young children that may be associated with developmental programming of asthma and related phenotypes at an age when sedentary behaviour may be common. ${ }^{10}$ There is some circumstantial evidence to suggest that respiratory patterns associated with sedentary activities, such as spontaneous sigh rates, ${ }^{11}$ may be important in regulation of airway smooth muscle tone and consequently airway responsiveness. 
Failure to stretch airway smooth muscle by regular deep inspiration could lead to increased airway responsiveness, ${ }^{36}$ and this mechanism has been proposed as a potential contributor to the recent rise in the prevalence of asthma. ${ }^{22}$ However, we did not show any direct association between sedentary behaviour and BHR, nor were we able to demonstrate a stronger effect of sedentary behaviour in those children with BHR.

\section{CONCLUSION}

In summary, increased duration of TV viewing in early childhood is associated with the subsequent development of asthma. This relationship was not gender-specific, was not modified by body mass and was independent of current sedentary behaviour at 11 years of age. Although physical training interventions have been studied in the management of established asthma symptoms, the role of habitual physical activity levels in the inception and natural history of asthma in children deserves further study.

Acknowledgements: The authors thank all the families who took part in this study, the midwives for their help in recruiting them and the whole ALSPAC team which includes interviewers, computer and laboratory technicians, clerical workers, research scientists, volunteers, managers, receptionists and nurses. The UK Medical Research Council, the Wellcome Trust and the University of Bristol provide core support for ALSPAC. This publication is the work of the authors.

JH and AS had the idea for the study. JH, AS, JJR, JYP designed the study. AS analysed the data. CM, ARN and CR developed, collected and analysed the physical activity data. All the authors actively participated in study management, the interpretation of results and the writing of the paper. All contributors contributed to and approved the final version of the manuscript. AS will serve as a guarantor for the contents of this paper and had final responsibility for the decision to submit for publication.

Funding: AS was funded by Medical Research grant MRC G0401540. The funding source had no involvement in the authors' work.

Competing interests: None.

Ethics approval: Ethical approval for the study was obtained from the ALSPAC Law and Ethics Committee and the local research ethics committees.

\section{REFERENCES}

1. Anderson HR, Gupta R, Strachan DP, et al. 50 years of asthma: UK trends from 1955 to 2004. Thorax 2007:62:85-90.

2. Figueroa-Munoz JI, Chinn S, Rona RJ. Association between obesity and asthma in 4-11 year old children in the UK. Thorax 2001;56:133-7.

3. von Mutius E, Schwartz J, Neas LM, et al. Relation of body mass index to asthma and atopy in children: the National Health and Nutrition Examination Study III. Thorax 2001;56:835-8.

4. Oddy WH, Sherriff JL, de Klerk NH, et al. Breastfeeding, body mass index, and asthma and atopy in children. Adv Exp Med Biol 2004;554:387-90.

5. Wickens K, Barry D, Friezema A, et al. Obesity and asthma in 11-12 year old New Zealand children in 1989 and 2000. Thorax 2005:60:7-12.

6. Chinn S. Obesity and asthma. Paediatr Respir Rev 2006;7:223-8.

7. Eijkemans M, Mommers M, de Vries SI, et al. Asthmatic symptoms, physical activity, and overweight in young children: a cohort study. Pediatrics 2008;121:e666-72.

8. Dollman J, Norton K, Norton L. Evidence for secular trends in children's physical activity behaviour. Br J Sports Med 2005;39:892-7.

9. Schools Health Education Unit. Trends: young people and physical activity attitudes and participation in exercise and sport 1987-2003. Exeter: SHEU Publications, 2004
10. Reilly JJ, Jackson DM, Montgomery C, et al. Total energy expenditure and physical activity in young Scottish children: mixed longitudinal study. Lancet 2004;363:211-2.

11. Hark WT, Thompson WM, McLaughlin TE, et al. Spontaneous sigh rates during sedentary activity: watching television vs reading. Ann Allergy Asthma Immunol 2005;94:247-50.

12. Mattocks C, Ness A, Deere K, et al. Early life determinants of physical activity in 11 to 12 year olds: cohort study. BMJ 2008;336:26-9.

13. Van der Horst K, Paw MJ, Twisk JW, et al. A brief review on correlates of physical activity and sedentariness in youth. Med Sci Sports Exerc 2007;39:1241-50.

14. Mancuso CA, Sayles W, Robbins L, et al. Barriers and facilitators to healthy physical activity in asthma patients. J Asthma 2006;43:137-43.

15. Glazebrook C, McPherson AC, Macdonald IA, et al. Asthma as a barrier to children's physical activity: implications for body mass index and mental health. Pediatrics 2006;118:2443-9.

16. Tsai HJ, Tsai AC, Nriagu J, et al. Associations of BMI, TV-watching time, and physical activity on respiratory symptoms and asthma in 5th grade schoolchildren in Taipei, Taiwan. J Asthma 2007;44:397-401.

17. Priftis KN, Panagiotakos DB, Anthracopoulos MB, et al. Aims, methods and preliminary findings of the Physical Activity, Nutrition and Allergies in Children Examined in Athens (PANACEA) epidemiological study. BMC Public Health 2007:7:140.

18. Firrincieli V, Keller A, Ehrensberger R, et al. Decreased physical activity among Head Start children with a history of wheezing: use of an accelerometer to measure activity. Pediatr Pulmonol 2005:40:57-63.

19. Jones SE, Merkle SL, Fulton JE, et al. Relationship between asthma, overweight, and physical activity among U.S. high school students. J Community Health 2006:31:469-78.

20. Ownby DR, Peterson EL, Nelson D, et al. The relationship of physical activity and percentage of body fat to the risk of asthma in 8- to 10-year-old children. J Asthma 2007;:44:885-9.

21. Nystad W, Nafstad P, Harris JR. Physical activity affects the prevalence of reported wheeze. Eur J Epidemiol 2001;17:209-12.

22. Lucas SR, Platts-Mills TA. Physical activity and exercise in asthma: relevance to etiology and treatment. J Allergy Clin Immunol 2005;115:928-34.

23. Vogelberg $\mathbf{C}$, Hirsch $\mathrm{T}$, Radon $\mathrm{K}$, et al. Leisure time activity and new onset of wheezing during adolescence. Eur Respir J 2007;30:672-6.

24. Rasmussen F, Lambrechtsen J, Siersted HC, et al. Low physical fitness in childhood is associated with the development of asthma in young adulthood: the Odense Schoolchild Study. Eur Respir J 2000;16:866-70.

25. Golding J, Pembrey M, Jones R. ALSPAC—-the Avon Longitudinal Study of Parents and Children. I. Study methodology. Paediatr Perinat Epidemiol 2001;15:74-87.

26. Yan K, Salome C, Woolcock AJ. Rapid method for measurement of bronchial responsiveness. Thorax 1983;38:760-5.

27. Mattocks C, Ness A, Leary S, et al. Use of accelerometers in a large field-based study of children: protocols, design issues, and effects on precision. J Phys Act Health 2008;5(Suppl 1):S98-111.

28. Ness AR, Leary SD, Mattocks $C$, et al. Objectively measured physical activity and fat mass in a large cohort of children. PLoS Med 2007;4:e97.

29. Reilly JJ, Armstrong J, Dorosty AR, et al. Early life risk factors for obesity in childhood: cohort study. BMJ 2005;330:1357.

30. Dennison BA, Erb TA, Jenkins PL. Television viewing and television in bedroom associated with overweight risk among low-income preschool children. Pediatrics 2002; 109:1028-35.

31. Jago R, Baranowski T, Baranowski JC, et al. BMl from 3-6 y of age is predicted by TV viewing and physical activity, not diet. Int J Obes (Lond) 2005:29:557-64.

32. Shaaban R, Leynaert B, Soussan D, et al. Physical activity and bronchial hyperresponsiveness: European Community Respiratory Health Survey II. Thorax 2007:62:403-10.

33. McConnell R, Berhane K, Gilliland F, et al. Asthma in exercising children exposed to ozone: a cohort study. Lancet 2002;359:386-91.

34. Ram FS, Robinson SM, Black PN, et al. Physical training for asthma. Cochrane Database Syst Rev 2005:(4):CD001116.

35. Grund A, Krause $\mathrm{H}$, Siewers $\mathbf{M}$, et al. Is TV viewing an index of physical activity and fitness in overweight and normal weight children? Public Health Nutr 2001:4:1245-51.

36. Skloot G, Permutt S, Togias A. Airway hyperresponsiveness in asthma: a problem of limited smooth muscle relaxation with inspiration. J Clin Invest 1995:96:2393-403. 